\title{
Optimization for an efficient and highly productive turning process
}

\author{
Sonja Jozić ${ }^{1}$, Dražen Bajić ${ }^{1}$, Ivana Dumanić ${ }^{1}$, Željko Bagavac ${ }^{1}$ \\ ${ }^{1}$ Faculty of Electrical Engineering, Mechanical Engineering and Naval Architecture, University of Split, e-mail: \\ sjozic@fesb.hr, dbajic@fesb.hr, $\underline{\text { iduman00@fesb.hr, zeljko.bagavac@ @esb.hr }}$
}

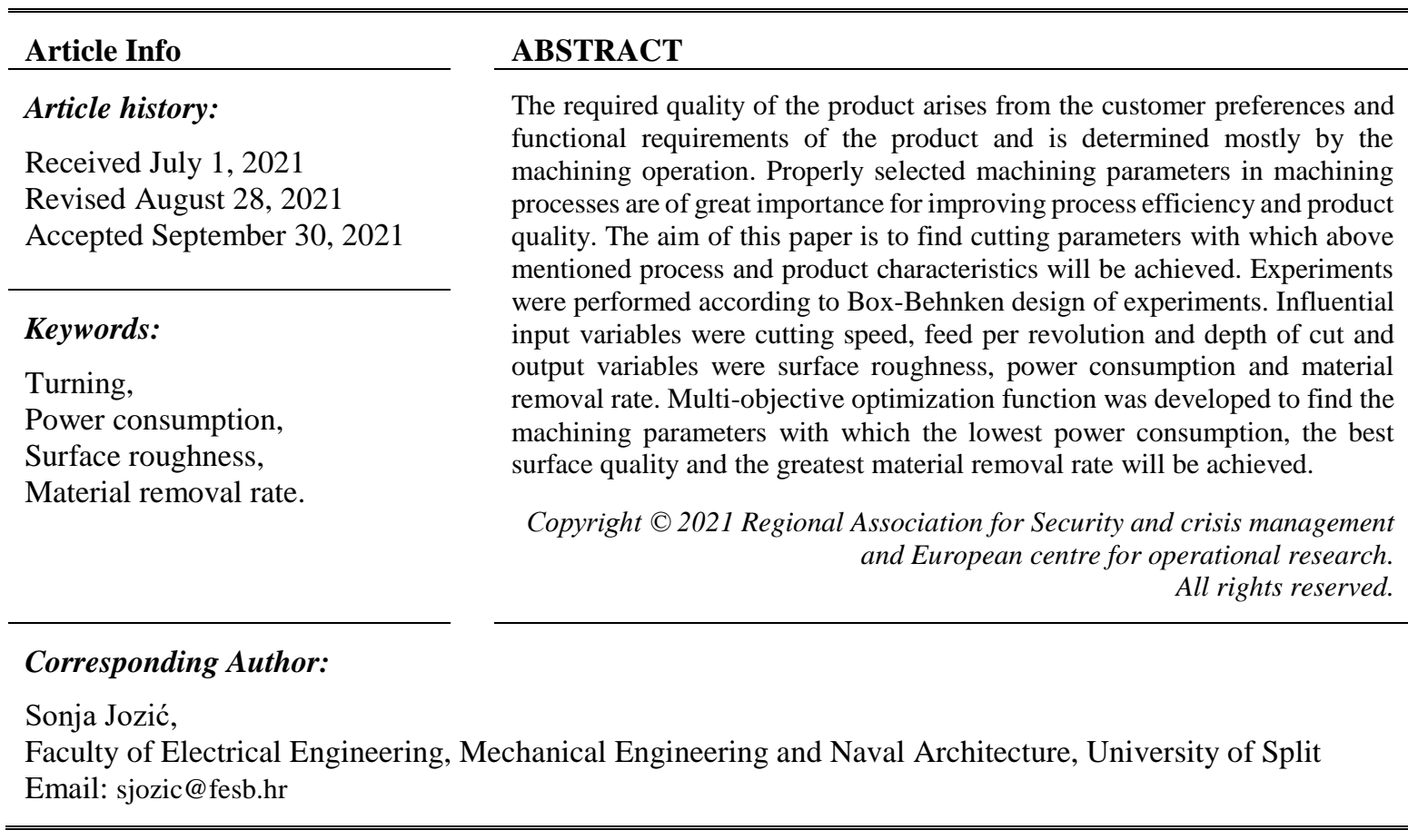

\section{Introduction}

One of the most significant results of globalization is expansion of available market. The global market and the great importance of environmental issues are the main reasons for raising the awareness of the manufacturing industry for balanced energy consumption, production rate and product quality. In the past, the development of technology was slow and there was no strong competition. The price of the product was formed depending on the cost and the desired profit. Nowadays, the widespread market has brought strong competition. The price of the product has begun to be dictated by the market, and manufacturer must ensure profit by reducing costs.

Currently, many manufacturers involve high technologies in their production process, and the production of quality products has become an obligation in order to survive on the world market. Since the production of quality products requires high production costs, it is necessary to find a way to increase market competitiveness. The most effective way is to reduce production costs while maintaining existing quality (Pimenov et al. 2020).

There is also the ubiquitous and well-known need to achieve general sustainability in industrial activities. The concept of sustainable development today is one of the most present concepts in science, media and civil society and is considered a necessary environment to ensure the future of the Earth. The most well-known definition of sustainable development is one that emphasizes how all needs should be met without compromising the ability to meet the needs of future generations. Sustainable development in the manufacturing industry as one of the largest sources of environmental pollution imposes the need to find new technologies and ways that could be used with minimal consequences for man and the environment (Sharma et al. 2017). 
Most out of the large number of researches, conducted in the area of machining, is focused on its activities and improvement of the process itself. Some of these improvements, such as optimization of machining, minimizing use of cutting fluids and reduction of energy consumption necessary to remove the material from workpiece, have important positive consequences for the environment, (Fernando et al., 2021; Davim, 2013; Young et al., 2012).

For example, usage of cutting fluids causing serious health and environmental problems arising from their application often opens new research fields for the purpose of solving the above mentioned problems. Strict regulations on use and disposal and higher purchase price, costs of cutting fluids which in the 80-ies of the last century made about $3 \%$ of machining costs now reach the level of $17 \%$ (Youssef \& El-Hofy, 2008). For the sake of comparison, costs of purchase and replacement of tools represent a share of $2 \%$ to $4 \%$ of production costs. Also, some studies showed that out of the total power consumption necessary for machining, almost $60 \%$ is used for procurement and supply of cutting fluids, which makes a serious problem considering the trend of permanent growth of energy resources in the previous decade (Rahäuser et al., 2011). Earlier research has found that machine tools have less than $30 \%$ energy efficiency and at the same time $99 \%$ have a detrimental effect on the environment due to exceptional power consumption, (Li et al., 2011).

The service life and performance of the product directly depend on the surface roughness, so significant attention is paid to determining the machining parameters that will ensure satisfactory surface roughness. The goal of the metalworking industry is higher productivity which is expressed through the material removal rate (MRR). But recently, rational electricity consumption has also emerged in the efficiency equation as an important goal of optimizing the machining process. Guo et al. (2012) have determined optimal cutting parameters to accomplish a precise surface finish with minimum energy consumption. They used energy and surface quality models, took into account the machine tool, workpiece diameter and obtained optimal cutting parameters that should ensure the best process performance. Öztürk and Kara (2020) by means of ANOVA have showed how to determine the cutting parameters in milling process which are effective on energy consumption and surface roughness were determined via ANOVA. Sangwana and Kant, (2017) presented a predictive and optimization model based on response surface methodology and genetic algorithm, determined cutting parameter by which they improved energy efficiency during turning AISI 1045 steel. Khanna et al., (2020) have seek an improvement in the machinability of Inconel 718. They have critically examined industryrelevant machinability indicators namely energy consumption, chip reduction coefficient (CRC), and average surface roughness $(\mathrm{Ra})$ and material removal rates (MRR) under different cutting environments. Nowadays, enhanced productivity could be achieved by CNC technology. Sarker and Chakraborty, (2021), applied discriminant analysis to examine the effect of cutting parameters, tool geometry, machining environment on surface roughness, tool life, cutting forces and power consumption. In their paper, Pawanr et al. (2021) tried and succeeded to make a model energy consumed during variable removal rate machining process like face turning, grooving etc. during the $\mathrm{CNC}$ turning.

The aim of this paper is to predict the quality of the machined surface, power consumption and machining efficiency expressed as the amount of removed material per unit time in longitudinal turning. Based on mathematical models, it is necessary to find machining parameters that will ensure at the same time satisfactory quality of the machined surface, minimum power consumption and maximum process efficiency. In this way, the utilization of production capacities would be maximized and market competitiveness would be increased.

\section{Power required for turning}

Understanding the machine tools energy performances and determining targeted energy saving measures require detailed study of energy efficiency in the industry of machining. Determination of energy consumption in the machining process is taking into account the consumption of electricity at idle and during machining operation. During machining, it is necessary to overcome the cutting resistances at a certain cutting speed $v_{c}$, Figure 1. and the frictional resistances in the machine tool with the power of the electric drive motor.

The power of the electric drive motor can be expressed as:

$P_{E M}=P_{i d}+P_{e f}=P_{i d}+P_{F c}+P_{F p}+P_{F f}$

$P_{i d}$ - power at idle $[\mathrm{W}]$

$P_{F C}$ - power required to remove the material [W]

$P_{F p}$ - power required for penetration into the material [W]

$P_{F f}$ - power required for motion in feed direction [W] 
Power at idle, $P_{i d}$, is used to overcome friction and other resistances in the machine tool. Its value is variable and increases with increasing load, because of increasing of losses and pressures in the bearings and due to heating, the coefficient of friction also changes. Therefore, the power at idle can be considered as the sum of the power at idle consumption of the unloaded machine tool and the power consumption due to additional load resistances, but only until the moment of removing the material, as it can be seen in Figure 2.

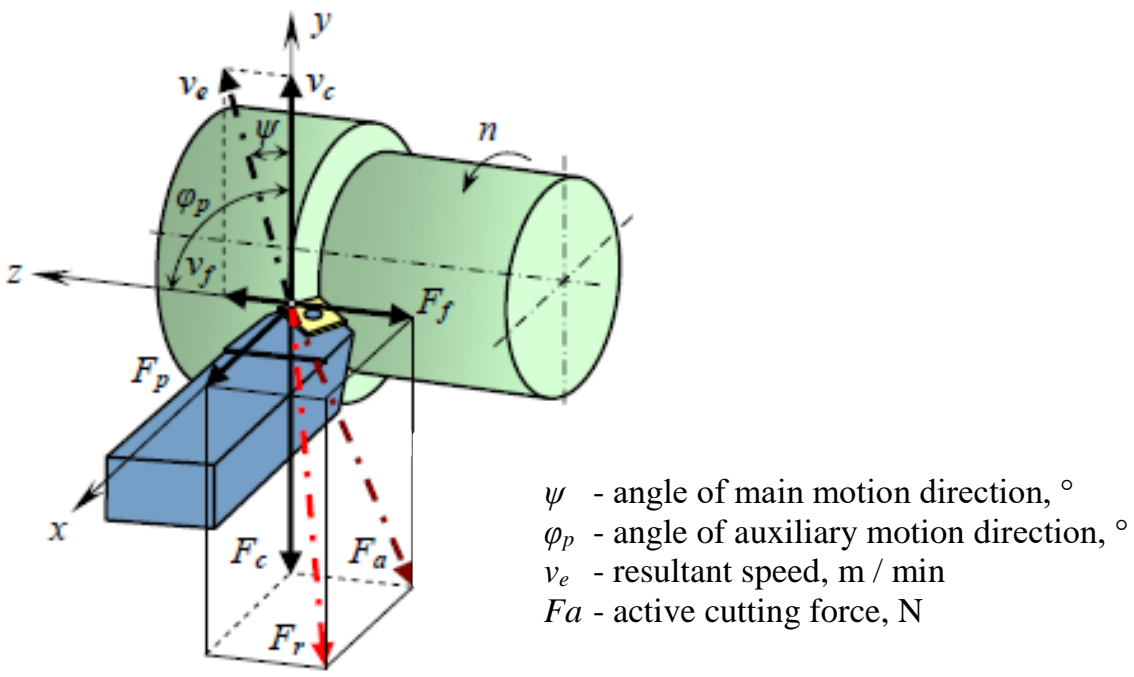

Figure 1. Cutting force and velocity components in longitudinal turning

The power required to remove the workpiece material $P_{F c}$ depends on the cutting speed $v_{c}$ and the main cutting force $F_{c}$.

$$
P_{F C}=F_{C} \cdot v_{c}
$$

The power required for penetration into the material $P_{F p}$ is equal to zero for longitudinal turning because the penetration speed $v_{p}$ is equal to zero.

The power required for motion in feed direction $P_{F f}$ is the force required to overcome the resistance during feed motion, and is calculated as follows:

$P_{F f}=F_{f} \cdot f_{n} \cdot n$

$F_{f}-$ feed force $[\mathrm{N}]$

$f_{n}-$ feed per revolution $[\mathrm{mm} / \mathrm{r}]$

$n$ - spindle speed (number of revolutions) $\left[\mathrm{min}^{-1}\right]$

It follows from the above that the useful power $P_{e f}$ consists of:

$P_{e f}=P_{F c}+P_{F f}$

The power $P_{F f}$ is very small in relation to the power of $P_{F c}$ and can be neglected, therefore the power of the electric drive motor needed for longitudinal turning can be expressed as:

$P_{E M}=P_{i d}+P_{e f}=P_{i d}+P_{F c}$

The expression also applies

$P_{E M}=\frac{P_{e f}}{\eta}$

$\eta$-degree of machine tool efficiency

Since:

$P_{e f} \approx P_{F c}=F_{c} \cdot v_{c}$

Finally, the total driving power can be expressed by equation:

$P_{E M}=\frac{F_{c} \cdot v_{c}}{\eta}$ 


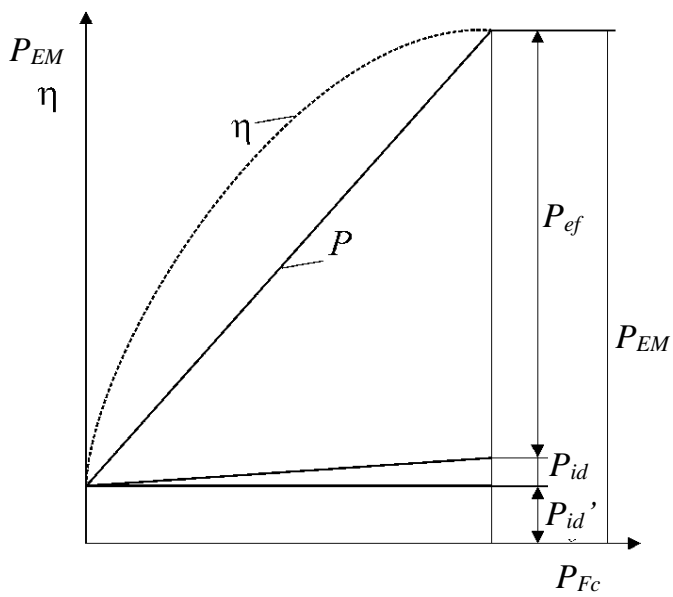

Figure 2. Power of electromotor and degree of efficiency dependence

By applying equations (1) to (8) it is possible to calculate the degree of efficiency of the machine tool and the main cutting force. Afterthat it is possible to calculate the specific cutting force, $k_{F c}$, if the cross-sectional area of the chip, $A$, is known and it is easily determined from the machining parameters.

$$
k_{F c}=\frac{F_{C}}{A}
$$

A measure of the efficiency of the turning process is the amount of removed material per unit time or material removal rate $(M R R) . M R R$ is calculated as follows:

$$
M R R=v_{c} \cdot a_{p} \cdot f
$$

\section{Experimental setup}

Experimental trials were performed on the universal lathe machine under dry cutting conditions. The aim was to obtain measurement results that will enable mathematical modeling for the selected output value of surface roughness $R a$, power consumption for cutting process $P$ and material removal rate $M R R$, as machining process efficiency indicator.

Longitudinal turning tests were carried out using tool holder PTGNR 2020K 16 manufactured by Sandvik and hard metal cutting insert, TNMG 1604 08-PF 4215 with CVD TiCN+Al2O3+TiN coating. Geometry and dimensions of the tool holder and inserts are presented in Figure 3.

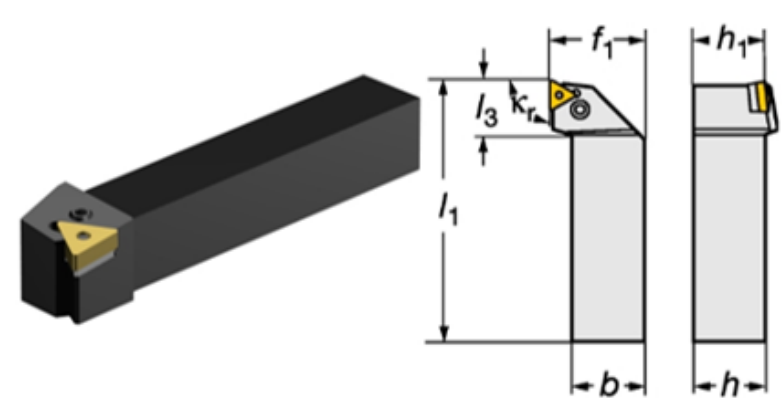

\begin{tabular}{cc}
\hline Parameter & Values \\
\hline weight & 0,4 \\
Insert size & 16 \\
$b$ & 20 \\
$f_{1}$ & 25 \\
$h$ & 20 \\
$h_{1}$ & 20 \\
$l_{1}$ & 125 \\
$l_{3}$ & 20,2 \\
$\kappa r$ & 91 \\
& \\
\hline Parameter & Values \\
\hline$l$ & 16 \\
$s$ & 4,76 \\
$r_{\varepsilon}$ & 0,8 \\
$i C$ & 9,52 \\
$f$ & $0,1-0,35$ \\
$a_{p}$ & $0,3-1,5$ \\
$v_{c}$ & $200-300$
\end{tabular}

Figure 3. Tool holder and insert with dimensions 
The workpiece material is 34CrNiMo6, a quenching and tempering steel with high strength, high toughness and good hardenability, with dimensions $\varnothing 50$ x $250 \mathrm{~mm}$. Chemical composition and mechanical properties of workpiece material are presented in Table 1.

Table 1. Chemical composition and mechanical properties of workpiece material 34CrNiMo6

\begin{tabular}{cccccc}
\hline \multicolumn{5}{c}{ Chemical composition, \% } \\
\hline $\mathrm{C}$ & $\mathrm{Si}$ & $\mathrm{Mn}$ & $\mathrm{Ni}$ & $\mathrm{Cr}$ & Mo \\
0.34 & 0.35 & 0.55 & 1.55 & 1.55 & 0.22 \\
\hline \multicolumn{5}{c}{ Mechanical properties } \\
\hline Brinell hardness & Yield strength & Tensile strength & Elongation at \\
$\mathrm{HB}$ & $\mathrm{R} \mathrm{p}_{0.2}[\mathrm{MPa}]$ & {$[\mathrm{MPa}]$} & fracture [\%] \\
\hline 250 & 900 & 1100 & 10 \\
\hline
\end{tabular}

Measurements of the surface roughness were performed by using profilometer Mitutoyo Surftest SJ301. Cutt-off length and the sampling length for surface measurements were selected to be $0.8 \mathrm{~mm}$ and $5.6 \mathrm{~mm}$, respectively. During the measurements, a minimum of three to five measurements were performed after each experiment, depending on the oscillations of the measurements, in order to more accurately determine the average results. The power consumpted for every combination of cutting parameters was measured with simple wattmeter.

\section{Experimental procedure}

The main goal of this study is to investigate the influence of cutting speed $v_{c}$, feed per revolution $f_{n}$ and depth of cut $a_{p}$ on surface roughness, power consumption and material removal rate in the longitudinal turning process. In order to determine mathematical models that could describe abovementioned output variables, design of experiment approach was used. In that purpose, response surface methodology (RSM) and BoxBehnken design (BBD) were selected. In the experimental research and modeling, BBD is very often used because it is not necessary to examine the end values (peaks), which are sometimes complicated to examine, it offers optimization possibility and reduction of the number of experiments. Three factorial BBDs of experiment demands 17 experiments, figure 4 .

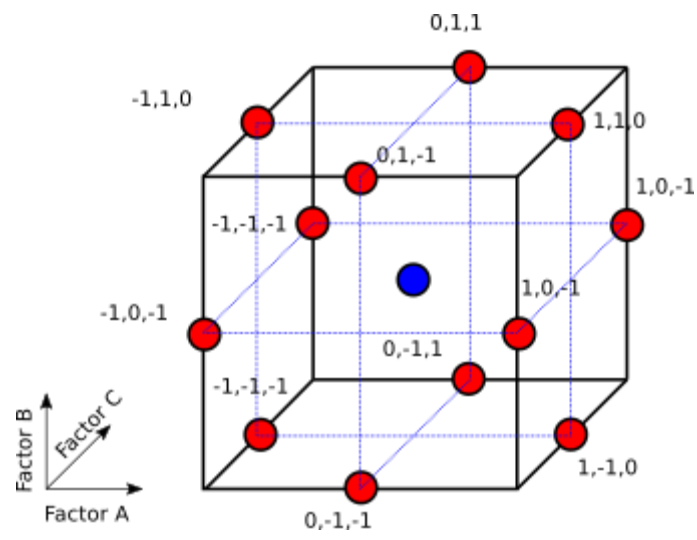

Figure 4. Box-Behnken design of experiments

Cutting parameters were varied in a specific range and are presented in Table 2. Cutting parameters are selected according to recommendation of tool manufacturers and mechanical properties of the workpiece materials. Experimental points, created according to BBD using "Design Expert" computer software, were presented together with experimental results in Table 3.

Table 2. Values of cutting parameters used for BBD

\begin{tabular}{ccc}
\hline Input variables & Minimal value & Maximal value \\
\hline Cutting speed $v_{c}[\mathrm{~m} / \mathrm{min}]$ & 60 & 130 \\
Feed per revolution $f_{n}[\mathrm{~mm} / \mathrm{r}]$ & 0.16 & 0.28 \\
\hline
\end{tabular}




$\begin{array}{lll}\text { Depth of cut } a_{p}[\mathrm{~mm}] & 0.6 & 1.2\end{array}$

Table 3. Experimental design, measured $(R a$ and $P)$ and calculated responses $(M R R)$

\begin{tabular}{crccccr}
\hline $\begin{array}{c}\text { Experiment } \\
\text { number }\end{array}$ & $\begin{array}{r}\text { Cutting } \\
\text { speed } v_{c} \\
{[\mathrm{~m} / \mathrm{min}]}\end{array}$ & Feed $f_{n}$ & $\begin{array}{c}\text { Depth of } \\
\text { cut } a_{p} \\
{[\mathrm{~mm} / \mathrm{r}]}\end{array}$ & $\begin{array}{c}\text { Surface } \\
\text { roughness } \\
R a[\mu \mathrm{m}]\end{array}$ & Power $P$ & MRR \\
\hline 1 & 95 & 0.22 & 0.9 & 0.76 & 2.60 & 18.81 \\
2 & 60 & 0.22 & 0.6 & 1.27 & 1.72 & 7.92 \\
3 & 60 & 0.16 & 0.9 & 0.62 & 1.77 & 8.64 \\
4 & 130 & 0.28 & 0.9 & 1.70 & 3.25 & 32.76 \\
5 & 95 & 0.28 & 1.2 & 1.58 & 2.90 & 31.92 \\
6 & 95 & 0.22 & 0.9 & 0.80 & 2.40 & 18.81 \\
7 & 60 & 0.28 & 0.9 & 1.90 & 1.88 & 15.12 \\
8 & 95 & 0.28 & 0.6 & 1.77 & 2.35 & 15.96 \\
9 & 130 & 0.22 & 0.6 & 0.80 & 3.20 & 17.16 \\
10 & 130 & 0.22 & 1.2 & 0.98 & 3.25 & 34.32 \\
11 & 130 & 0.16 & 0.9 & 0.52 & 3.30 & 18.72 \\
12 & 95 & 0.16 & 0.6 & 0.56 & 2.08 & 9.12 \\
13 & 95 & 0.22 & 0.9 & 0.80 & 2.47 & 18.81 \\
14 & 95 & 0.22 & 0.9 & 0.84 & 2.43 & 18.81 \\
15 & 95 & 0.16 & 1.2 & 0.58 & 2.63 & 18.24 \\
16 & 60 & 0.22 & 1.2 & 0.82 & 2.50 & 15.84 \\
17 & 95 & 0.22 & 0.9 & 1.05 & 2.05 & 18.81 \\
\hline
\end{tabular}

\section{Analysis of experimental data}

The response surface method is used to determine mathematical models for prediction of surface roughness, power consumption and material removal rate.

RSM is a set of mathematical and statistical methods that model and analyze the effects of several factors (independent variables) on the observed response. The basic idea of the response surface methodology is to obtain the relationship of influential (independent) factors to the dependent variable (response) through the response function. It is also possible to distinguish the effects of individual members of the model, as the main effects or interactions. As a condition for using RSM, there should be at least two independent variables and one dependent variable.

In most RSM problems, the form of the relationship between the response and the independent variables is unknown. Therefore, the first step in the RSM method is to search for an appropriate approximation relationship and independent variables. A lower order polynomial, first or second order, is usually used in the corresponding ranges of the independent variables. To develop a model between response and input variables with satisfactory accuracy, a second-order model was used as follows:

$y=b_{0}+\sum_{i=0}^{k} b_{i} x_{i}+\sum_{1 \leq i<j}^{k} b_{i j} x_{i} x_{j}+\sum_{i=1}^{k} b_{i i} x_{1}^{2}$

where:

- $b_{0}, b_{i}, b_{i j}, b_{i i}$ are the regression coefficients,

$-x_{i}, x_{j}$ are values of input parameters.

Results were inserted into computer software Design Expert where analysis of variance (ANOVA) and regression analysis (RA) were carried out resulting in mathematical models for $R a, P$ and $M R R$.

Surface roughness

Quadratic mathematical model for $R a$ was suggested and adopted, equation (12). R-Squared, Adj RSquared, Pred R-Squared, and Adeq Precision were obtained by using ANOVA and the values are 0.98, 0.95, 0.93 and 18.278, respectively.

$$
\begin{aligned}
& R a=3.852-0.027 \cdot v_{c}-17.057 \cdot f_{n}-1.636 \cdot a_{p}-0.012 \cdot v_{c} \cdot f_{n}+0.015 \cdot v_{c} \cdot a_{p}- \\
& 2.639 \cdot f_{n} \cdot a_{p}+7.143 \cdot 10^{-5} \cdot v_{c}^{2}+68.750 \cdot f_{n}^{2}+0.333 \cdot a_{p}^{2} \\
& \text { Optimization for an efficient and highly productive turning process (Sonja Jozić) }
\end{aligned}
$$




\section{Power consumption}

Linear mathematical model for power consumption, P, was suggested and adopted, equation (13). R-Squared, Adj RSquared, Pred R-Squared, and Adeq Precision were obtained by using ANOVA and the values are $0.87,0.84,0.78$ and 17.23 , respectively.

$$
P=-0.222+0.018 \cdot v_{c}+1.250 \cdot f_{n}+0.804 \cdot a_{p}
$$

\section{Material removal rate}

Sequential Model Sum of Squares, i.e. 2FI model for MRR was suggested and adopted, equation (14). RSquared, Adj RSquared, Pred R-Squared, and Adeq Precision were obtained by using ANOVA and the values are $0.99,0.99,0.99$ and 447.015, respectively.

$$
\begin{aligned}
& M R R=18.795-0.198 \cdot v_{c}-85.500 \cdot f_{n}-20.900 \cdot a_{p}+0.900 \cdot v_{c} \cdot f_{n}+0.220 \cdot v_{c} \cdot a_{p}+ \\
& 95.000 \cdot f_{n} \cdot a_{p}
\end{aligned}
$$

The response area could be plotted graphically throughout the experimental range, the range of possible factor combinations. This graphical representation allows a general view how the response varies as a function of the two factors chosen for display, while the third is at its middle level, Figures from 3 to 5 . Figure 3. a) shows the influence of cutting speed and feed per revolution on surface roughness, when depth of cut is $0.9 \mathrm{~mm}$ and is kept constant. It is obvious that both factors influence on surface roughness, but the feed per revolution has a more dominant effect.

Considering the influence of cutting depth and feed per revolution on the surface roughness, which is shown in Figure 3. b), it can be concluded that if the feed per revolution increases, the surface roughness increases as well. Increasing of depth of cut, when feed per revolution has a lower value, does not have a significant influence on the surface roughness. At higher values of feed per revolution, the influence of the cutting depth on the surface roughness increases, so that with increasing the depth of cut the surface roughness decreases. It can be explained that lower depth of cut causes the hardening of workpiece material resulting in an increase in cutting resistance. Increased cutting resistance leads to unstable machining, vibration and increased cutting forces, which has a negative effect on the roughness of the machined surface.
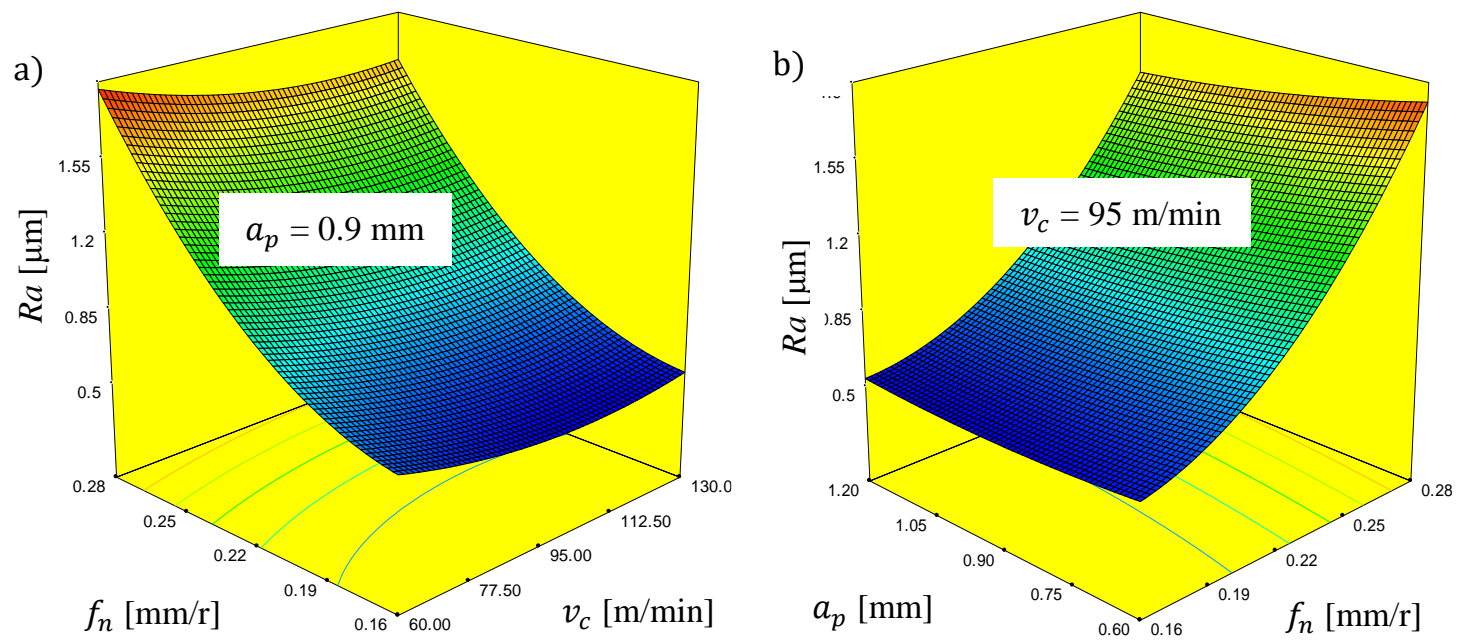

Figure 3. a) Influence of feed per revolution and cutting speed on surface roughness

b) Influence of depth of cut and feed per revolution on surface roughness

Figure 4. a) and b) show the dependence of the power consumption for machining operation on the cutting parameters. It can be observed, from the Figure 4. a), that the cutting speed compared to the depth of cut has a dominant influence on the power. The dependence is linear. If we observe the cutting depth and the feed per revolution, then it can be seen, in the Figure 4. b), that the depth of cut affects the power more than the feed per revolution. This can be explained by the fact that the cross-sectional shape of chips, i.e. the ratio of feed per revolution and depth of cut has a great influence on the cutting force, and consequently affects the power required to remove the material. 

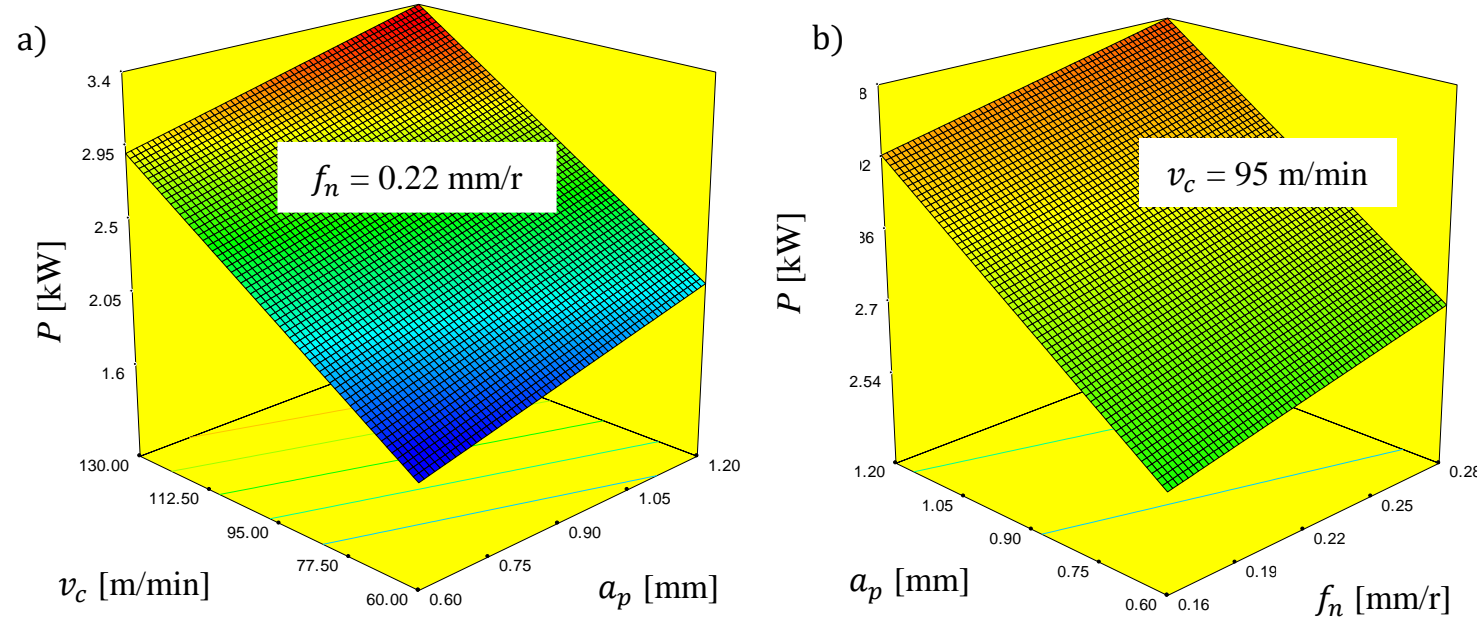

Figure 4. a) Influence of cutting speed and depth of cut on power consumption b) Influence of depth of cut and feed per revolution on power consumption

The highest material removal rates are achieved at maximum values of all cutting parameters: cutting speed, feed per revolution and depth of cut. As can be seen from the Figures 5 a) and b), all parameters more or less have the same effect on material removal rate.

a)

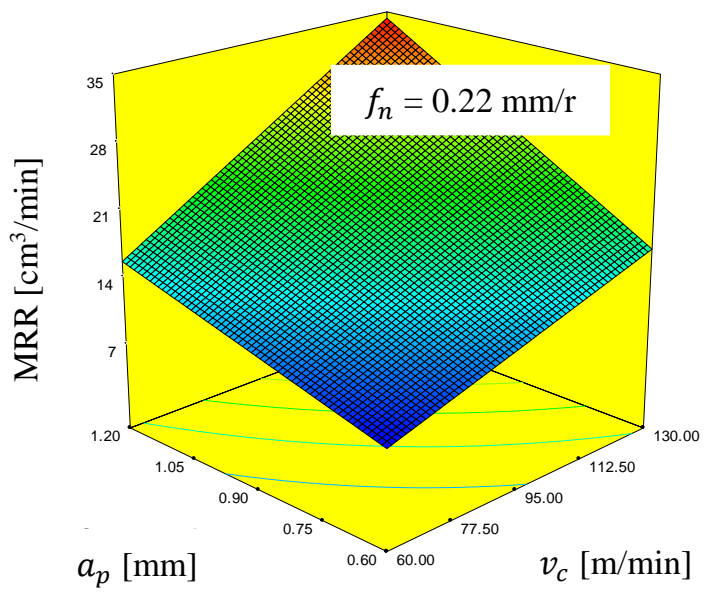

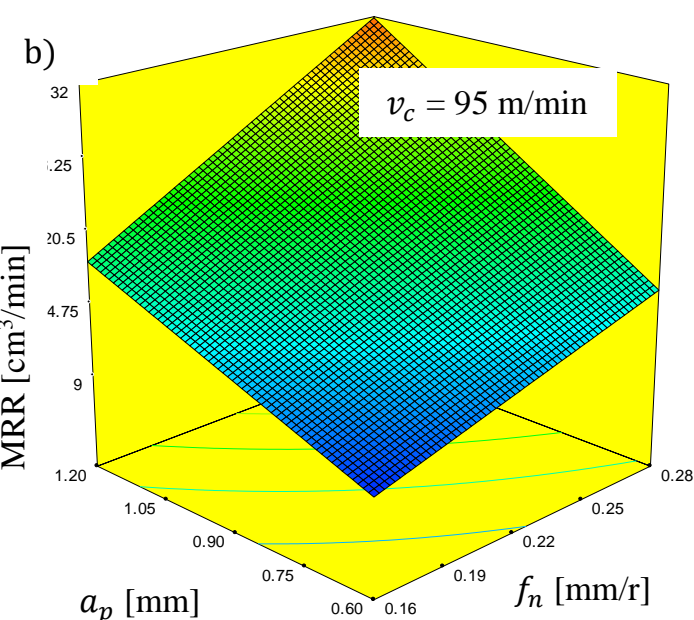

Figure 5. a) Influence of depth of cut and cutting speed on material removal rate b) Influence of depth of cut and feed per revolution on material removal rate

\section{Optimization by genetic algorithm}

The main problem that arises in the optimization of machining processes is the knowledge of the process itself. Before setting up the optimization model, it is necessary to define: process state functions, goal functions, constraint functions and optimization criteria.

The functions of the machining process are most often: cutting forces (resistances), cutting power, cutting temperature, tool wear, tool stability, surface roughness, etc. The functions of the goal are most often: machining time, machining costs, accuracy, productivity, profit and can be a combination of different functions of the process state. Constraint functions refer to constraints related to the characteristics of: machine, tool and workpiece. The optimization criteria are most often: minimization of processing time and costs or maximization of productivity and profit, although there may be others, such as achieving a given quality of the machined area. However, the task of optimization is not simple because many factors of the machining process are interrelated and the change of some affects each other.

Once the mathematical models have been defined and found to describe the output variables well, the next 
step is to optimize the machining parameters. These parameters should meet the requirements of minimum power consumption, minimum surface roughness and maximum material removal rate.

Unified criterion of excellence solutions and integrated objective function is formed by combining the partial set of criteria. In this paper the optimization is performed by using the sum of "weighted" criteria with weights $w_{i}$ that show the relative importance of each criterion in the overall excellence (Jozic et al., 2014):

$f(x)=\sum w_{i} f_{i}(x), \quad \sum w_{i}=1, \quad w_{i}>0$

where $f(\mathrm{X})$ is objective function for the design problem, $\mathrm{X}$ is $\mathrm{n}$-dimensional design vector, $w_{i}$ is weighted factor, $0 \leq w_{i} \leq 1$,

According to the goal of optimization, the problem is mathematically formulated as follows:

Minimize:

$$
\begin{aligned}
& f(x)=w_{1} \frac{R a}{R a^{*}}+w_{2} \frac{P}{P^{*}}-w_{3} \frac{M R R}{M R R^{*}} \\
& 1=w_{1}+w_{2}+w_{3}
\end{aligned}
$$

where:

$R a^{*}, P^{*}$ and $M R R^{*}$ are target numerical value.

Constraints of cutting parameters were determined with respect to type of turning, workpiece and tool material, physical possibilities of machine tool.

The optimization procedure using a genetic algorithm was performed in the Matlab software package. Before the optimization itself, it is necessary to choose the parameters of the genetic algorithm: population size -200 , number of generations - 200, probability of crossing -0.75 , probability of mutation 0.01 , crossing at two points, size of tournament selection - 5. Multicriteria optimization will be performed according to equation (16). Weighting factors vary according to the priority of a particular process. Optimal cutting parameters that satisfy the objective function are: $v_{c}=103.2 \mathrm{~m} / \mathrm{min}, f_{n}=0.199 \mathrm{~mm} / \mathrm{r}, a_{p}=1.19 \mathrm{~mm}$. The priority is set the same for all process functions, but it can be easily changed if necessary.

With these machining parameters, the following values of process functions are predicted: $R a=0.65 \mu \mathrm{m}$, $M R R=24.72 \mathrm{~cm}^{3} / \mathrm{min}$ and $\mathrm{P}=2.85 \mathrm{~kW}$.

\section{Conclusion}

The aim of this work was to find the optimal machining parameters at which the power consumption and the roughness of the machined surface will be minimal, and the material removal rate will have the maximum value in the longitudinal turning process. Box-Behnken's experimental design was selected to obtain seventeen experimental combinations of machining parameters. Experimental results were processed in the computer program Design Expert and mathematical predictive models were obtained.

Optimal machining parameters were obtained by using genetic algorithm and they are: $v_{c}=103.2 \mathrm{~m} / \mathrm{min}$, $f_{n}=0.199 \mathrm{~mm} / \mathrm{r}, a_{p}=1.19 \mathrm{~mm}$. With these parameters it is possible to performing machining process in very efficient way. The proposal for future work is the application of the described methodology with the use of cutting fluids and alternative means for cooling, lubricating and flushing.

\section{References}

Pimenov D.Yu., Abbas A. T., Gupta M. K., Erdakov I. N., Soliman M. S. \& El Rayes M. M. (2020). Investigations of surface quality and energy consumption associated with costs and material removal rate during face milling of AISI 1045 steel. The International Journal of Advanced Manufacturing Technology, $107,3511-3525$.

Davim, J. P. (2013). Green Manufacturing Processes and Systems, Materials Forming, Machining and Tribology, Springer Science+Business Media B.V.

Fernando, W. L. R., Karunathilake, H. P. \& Gamage, J. R. (2021). Strategies to reduce energy and metalworking fluid consumption for the sustainability of turning operation: A review. Cleaner Engineering and Technology, 3, 100100 
Guo, Y., Loenders, J., Duflou, J. \& Lauwers, B. (2012). Optimization of energy consumption and surface quality in finish turning, Procedia CIRP 1, $512-517$.

Jozić, S., Bajić, D., Samardžić, I., (2014). Contribution to the assessment of economic viability of hard milling process, Tehnički vjesnik (Technical Gazette) 21 (6), 1329-1336.

Khanna, N., Agrawal, C., Dogra, M. \& Pruncu, C. I. (2020). Evaluation of tool wear, energy consumption, and surface roughness during turning of Inconel 718 using sustainable machining technique, Journal of materials research and technology, 9(3), 5794-5804.

Li, W., Zein, A., Kara, S. \& Herrmann, C. (2011). An Investigation into Fixed Energy Consumption of Machine Tools, Glocalized Solutions for Sustainability in Manufacturing. Proceedings of the 18th CIRP International Conference on Life Cycle Engineering, J. Hesselbach, and C. Herrmann, eds., Springer Berlin Heidelberg, Berlin, Heidelberg, 268-275.

Ozturk, B. \& Kara, F. (2020). Calculation and Estimation of Surface Roughness and Energy Consumption in Milling of 6061 Alloy. Advances in Materials Science and Engineering. Volume 2020, Article ID 5687951.

Pawanr, S., Garg, G. K. \& Routroy, S. (2021). Modelling of Variable Energy Consumption for CNC Machine Tools, Procedia CIRP 98, 247-251.

Rahäuser R., Pflüger T. \& Regenfelder M. (2011). Economic potentials of improvements of energy efficiency in the supply of cooling lubricants for metal cutting machine tools. Proceedings of the MOTSP 2011 International Conference on Management of Technology - Step to Sustainable Production, Brac, Croatia

Sangwana, K. S., \& Kant, G. (2017). Optimization of Machining Parameters for Improving Energy Efficiency using Integrated Response Surface Methodology and Genetic Algorithm Approach, Procedia CIRP 61, 517 522.

Sarker, B. \& Chakraborty, S. (2021). Parametric study of a CNC turning process using discriminant analysis, Facta universitatis, Series: Mechanical Engineering, https://doi.org/10.22190/FUME210403058S

Singh, G., \& Sharma, V. S. (2017). Analyzing machining parameters for commercially puretitanium (Grade 2), cooled using minimum quantity lubrication assisted by a Ranque-Hilsch vortex tube. The International Journal of Advanced Manufacturing Technology, 88(9-12), 2921-2928.

Young P., Byrne G., Cotterell M. (2012). Manufacturing and the Environment, International Journal of Precision Engineering and Manufacturing, 13 (7), 488-493.

Youssef, H. A. \& El-Hofy, H. (2008). Machining Technology: Machine Tools and Operations, CRC Press, Taylor and Francis Group. 